\title{
Determinants of IT Innovation Diffusion from Dynamic Perspective-Review and Prospects
}

\author{
Mingwang Lei \\ Department of Marketing, Management School, Jinan University, Guangzhou, China \\ Email: brynjolf@163.com
}

Received 14 January 2016; accepted 15 February 2016; published 18 February 2016

Copyright () 2016 by author and Scientific Research Publishing Inc.

This work is licensed under the Creative Commons Attribution International License (CC BY). http://creativecommons.org/licenses/by/4.0/

(c) (i) Open Access

\begin{abstract}
The research on information technology (IT) innovation at organizational level has gained plentiful and substantial achievements; existing research in this field presents the pattern of perspective diversification. This paper first introduces the concept of IT innovation and innovation diffusion, and then reviews five dynamic perspectives on the study of the influence factors of IT innovation diffusion, which are organizational learning, social contagion, management fashion, organizing vision and computerization movement. Suggestions and expectations are presented at the end of this paper.
\end{abstract}

\section{Keywords}

IT Innovation, Innovation Diffusion, Dynamic Perspective

\section{Introduction}

IT innovation diffusion at organizational level is an important genre in the research of IT innovation, and the research in this field has achieved fruitful results. Scholars always pay attention to the questions that why organizations adopt IT innovation and what factors affect innovation diffusion within the organization. Existing research in this field presents the pattern of perspective diversification.

Under the dominant research paradigm, scholars commonly apply economic-rationalistic logic to explain the behavior of IT innovation, assume that the organization will rational think about the fact that if it possesses the technical factors, organizational factors and environmental factors which are called "the right stuff" when make IT innovation adoption decision. Technology-organization-environment (TOE) model has widely applicability and strong explanatory power, get the support of a large number of empirical studies, and has become the most 
well-known and widely used model in the field of organizational IT innovation diffusion research. Fichman (2004) [1] proposed that future research should go beyond the dominant paradigm and got positive response from a large number of scholars (e.g. Melville and Ramirez, 2008 [2]; Wang, 2009 [3]; kaganer, 2010 [4]). Some dynamic perspectives and related theories begin to be concerned by the academic circles.

This paper first introduces the concept of IT innovation and innovation diffusion, then summarizes the dynamic research perspectives of IT innovation diffusion, finally, puts forward some suggestions for future research in IT innovation field.

\section{Concept of IT Innovation and Innovation Diffusion}

A lot of scholars have defined organizational innovation, the definition which Daft (1978) [5] proposed has been widely accepted: it involves adoption of an idea, material artifact, or behavior that is new to the organization adopting it. Definition of IT innovation was developed from the concept of organizational innovation. Lind and Zmud (1991) [6] thought IT innovation refers to administrative or operational ideas, practices, or objects perceived as new by an organizational unit and whose underlying basis lies with information technology. The most widely accepted definition of IT innovation was proposed by Swanson (1994) [7]: innovation in the organizational application of digital computer and communications technologies. He also stressed that IT innovation include not only new IT products or services, the use of new information and communication technologies, but also include rearranging the organization structure to manage and deliver IT services. Lyytinen and Rose (2003) [8] thought IT innovation involve technological components (e.g. new hardware and software) and organizational dimensions (e.g. new forms of work, business process and organizational structure). Fichman et al. (2014) [9] provided a more clearer definition of IT innovation: a product, process or business model that is perceived as new, requires significant changes on the part of adopters, and is embodied in or enabled by IT.

IT innovation and innovation diffusion are interrelated. Theory of innovation diffusion proposed by Rogers (1983) [10] divided the process of individual innovation adoption into four stages, they are knowledge, persuasion, decision, and confirmation. Scholars applied this theory to the organizational level, and on this basis, they divided the process of innovation diffusion into different stages. Cooper and Zmud (1990) [11] thought the process of IT innovation can be divided into six stages: initiation, adoption, adaptation, acceptance, routinization, infusion. Swanson and Ramiller (2004) [12] identified four stages: comprehension, adoption, implementation, and assimilation. There were some scholars defined IT innovation itself as a diffusion process, for example, Fichman and Melville (2014) [13] summarized the IT innovation definition as the whole process of the organization to adopt, implement and absorb the novel IT.

\section{Research on the Influencing Factors of IT Innovation Diffusion from Dynamic Perspective}

The rise of dynamic perspectives will help scholars to further explore the diffusion of IT innovation in the organization, the entire industry and even the whole social environment, make up the shortage of static research. Studying industry-level phenomena hold great potential to provide new insight for IT innovation diffusion research [2]. Kaganer et al. (2010) [4] also believed that one of the more fertile avenues for innovation research outside of the dominant paradigm is to explore socio-cognitive dynamics underlying innovation diffusion processes at the inter-organizational level of analysis. Wang (2010) [14] suggested that IT innovations cannot be fully understood without consider the social context of their development and usage.

Existing IT innovation diffusion research shows different dynamic perspectives, according to the focus of concern in the research, I classify them into five types: organizational learning, social contagion, management fashion, organizing vision and computerization movement (as shown in Table 1).

\subsection{Organizational Learning}

Research based on organizational learning perspective consider IT innovation diffusion to be the result of the learning process, emphasizing learning within a single organization and biased in favor of learning-by-doing [15]. In the face of complex technology, organization usually formed knowledge barriers due to the learning burden, and will delay the adoption of complex technology until the knowledge barriers were lowered, or until the organization obtained enough skills to successfully implement and use the technology [16]. Fichman and Kemerer (1999) [17] argued that knowledge barrier is one of the reasons that lead to assimilation gap in the 
Table 1. Dynamic perspectives of IT innovation diffusion research.

\begin{tabular}{|c|c|c|c|}
\hline Dynamic perspectives & Theory bases & Core ideas & Researches \\
\hline Organizational learning & $\begin{array}{l}\text { Learning theory; } \\
\text { Absorptive capacity theory }\end{array}$ & $\begin{array}{l}\text { The existence of knowledge barriers allow the organization to } \\
\text { delay the adoption of IT innovations until the organization has } \\
\text { acquired sufficient skills through continuous learning to } \\
\text { implement and operate the technology successfully. }\end{array}$ & [18] [19] [21] \\
\hline Social contagion & $\begin{array}{l}\text { Institutional theory; } \\
\text { Neo-institutional theory; } \\
\text { Learning theory }\end{array}$ & $\begin{array}{l}\text { The prior IT innovation adopters are the "carriers" of } \\
\text { contagious influence, the more of their number, the stronger the } \\
\text { infectious of innovation. }\end{array}$ & {$[24][25][26]$} \\
\hline Management fashion & $\begin{array}{l}\text { Speech community theory; } \\
\text { Institutional theory }\end{array}$ & $\begin{array}{l}\text { Community members participate in the discussion of innovation } \\
\text { with their own motives, so that the community is full of } \\
\text { speeches about the IT innovation and form a fashion trend. }\end{array}$ & [3] [12] [14] \\
\hline Organizing vision & $\begin{array}{l}\text { Speech community theory; } \\
\text { Learning theory }\end{array}$ & $\begin{array}{l}\text { Organizing visions go beyond mere fashion statements to } \\
\text { synthesize and carry community wisdom that may draw from or } \\
\text { support real learning. }\end{array}$ & [4] [28] \\
\hline $\begin{array}{l}\text { Computerization } \\
\text { movement }\end{array}$ & $\begin{array}{l}\text { Social movement theory; } \\
\text { Rhetorical theory }\end{array}$ & $\begin{array}{l}\text { IT innovation diffusion is the product of social movements, the } \\
\text { technology behavior structure and the participants ideology can } \\
\text { represent by the competitive discourses, promote the } \\
\text { development of movements. }\end{array}$ & [31] [34] \\
\hline
\end{tabular}

The chart source: according to the relevant literature review.

process of IT innovation, organizations adopt the new information technologies might not be able to deploy them. Therefore, organizational learning is an important perspective for exploring IT innovation diffusion.

Fichman and Kemerer (1997) [18] considered that organizations with greater learning-related scale have a greater opportunity to capture economies of scale in learning, and learning costs are more likely to be diluted. Organizations that have more related knowledge, the knowledge and behavior are more diversity, are more likely to accept or learning new knowledge needed for innovation. Results of empirical study show that learning-related scale, related knowledge and diversity of knowledge have positive impact on the assimilation of object-oriented programming languages (OOPLs) within the organization.

From the perspective of organizational learning based on experience, Sherif et al. (2006) [19] studied the goal conflict problems of software reuse in the process of assimilation. He considered that the organization conduct conceptual and operational learning based on past experience, and form innovation-related knowledge along with the accumulation of experience. Then, the rich knowledge can reduce the level of conflict in the process of IT innovation assimilation. Research results show that organizational learning have negative influence on goal conflict, so as to ensure the assimilation of IT innovation inside the organization, and then bring a series of output of software reuse.

Many scholars (e.g. Carlo et al., 2012 [20]; Saraf et al., 2013 [21]; Cooper and Molla, 2014 [22]) studied IT innovation of enterprises from the perspective of organizational learning based on absorptive capacity. Organization developed absorptive capacity in the process of recognize, absorb, transform and apply valuable external knowledge, and actively affect the assimilation of complexity IT innovation [23]. Carlo et al. (2012) [20] studied the organizational IT innovation behavior from the cognitive and behavioral dimensions of absorptive capacity. Study results show that the more diverse and linkable of existing knowledge, the more perception of innovation-related knowledge from external environment, and organization can improve the level of innovation through learning this knowledge, finally resulting in IT base innovation and IT process innovation.

\subsection{Social Contagion}

Social contagion refers to a series of processes that prior adopters of IT innovations cause contagious influence to the organizations which have not yet adopt the IT innovations. When more and more organizations adopt the innovation, nonadopters will feel the social pressure, thus forming the phenomenon of social contagion. Social contagion view explain IT innovation diffusion mainly by neo-institutional theory and social learning theory. Neo-institutional theory is concerned with institutional forces (e.g. coercive force, normative force and mimetic force) that lead firms residing in an organizational field to increasingly resemble each other, resulting in institutional isomorphism. Social learning theory overlaps with the mimetic force in positing that people engage in a 
process of social learning by examining the actions of similar peers [1]. All prior adopters can be viewed as "carriers" or sources of contagious influence. The role of institutional forces, inter-organizational observation, information transmission and imitation learning made the nonadopters infected with the source of infection [24].

The social contagion phenomenon in the field of IT innovation has been paid more and more attention by scholars. Teo et al. (2003) [25] first applied the institutional theory to study the adoption of enterprise financial electronic data interchange (FEDI) system. The empirical results show that the coercive force, normative force and mimetic force which exist in external institutional environment positively impact the adoption of the FEDI system within organization. Liang et al. (2007) [26] believed that the institutional pressures not only affect the adoption and implementation of IT innovation in enterprises, but also affect the assimilation of innovation. Take the enterprise resource planning (ERP) system as the research object, the results of the study support their views. Angst et al. (2010) [24] believed that infection is a complex and dynamic process, the study of social contagion must consider three factors of organizational social structure: susceptibility of nonadopters, infectiousness of infestor, physical and social proximity between nonadopters and infection source. The empirical results show that the above factors have significant relationship with social contagion.

\subsection{Management Fashion}

In the field of IT, fashion is a common phenomenon [27]. Though IT innovations always have technical component, they are also managerial innovations [28]. Management fashion plays a significant role in the process of IT innovation diffusion.

Management fashion is a relatively transitory collective belief that an administrative technique is new, efficient, and at the forefront of management practice [29]. The basic concept that apply management fashion to IT innovation diffusion field is: technology suppliers, consultants, analysts, journalists, scholars and potential adoption organizations together to form a community, when IT innovation occurs, community members participate in the discussion of innovation with their own motives [3], which make community full of speeches about IT innovation and form a fashion trend of innovation. Managers are influenced by macro socio-psychological when actively looking for new technology, certain innovations may garner managerial attention and organizational adoption out of all proportion to the ultimate benefits flowing from their actual use [1] [14].

Wang (2009) [3] made an empirical study on popularity of ERP, he suggested that 1) the popularity of ERP was influenced positively by the prevalence of highlighted business problems that ERP was claimed to solve; 2) ERP's popularity was influenced negatively by the prevalence of related innovation concepts; and 3) these influences largely disappeared after ERP passed its peak popularity. Baskerville and Myers (2009) [27] argued that the popularity of IT in the community is the result of amplification. Community members may exaggerate the value of IT innovation, urgency of innovation adoption and ability to implement innovation based on their own purpose, lead IT innovation become a kind of fashion at a faster rate and attract more attention of manager, so as to promote the adoption of IT innovations.

Swanson and Ramiller (2004) [12] discussed the innovation behavior of two different types of enterprises under the tide of fashion. In the face of enterprise innovation, mindful firms will make inferences based on their own conditions. Therefore, the mindfulness innovation behaviors of mindful firms are rational, and this type of firms may produce a boycott of the fashion tide. The mindless firms lack consideration of organization specific characteristic and pay little attention to identifying and exploring new IT innovations. Therefore, when the fashion wave of IT innovation formed, mindless firms are easily affected and usually adopt IT innovation without thinking. Hashim et al. (2014) [30] argued that fashion wave easily lead to "me too", in this case, IT innovation adoption behaviors may be irregular, unnecessary and invalid, which is not conducive to the further diffusion of innovation. Their empirical research results confirmed that fashion effect have positive effect on innovation adoption, but is not conducive to the implementation of IT innovation.

\subsection{Organizing Vision}

Organizing vision is an important branch of IT innovation diffusion research in recent years [31]. An organizing vision is a focal community idea for the application of information technology in organizations, community members including technology suppliers, consultants, industry experts, prospective adopters and scholars [28] [12]. When IT innovation occurs, community members immediately open up discussion on some issues, such as the uncertainty and prospect of innovation, and how to embed and utilize information technology in organiza- 
tional structures and processes, thus forming a vision of IT innovation. If management fashion is temporary collective beliefs suspected of exemplifying superstitious learning, then organizing visions go beyond mere fashion statements to synthesize and carry community wisdom that may draw from or support real learning [15]. Organizing vision describes the usefulness and value of IT in a social way, making it easier for policymakers to decide whether to participate in innovation.

Swanson and Ramiller (1997) [28] believed that the organizing vision can promote the adoption and diffusion of IT innovation in organizations through three basic functions: interpretation, legitimation and mobilization. Kaganer et al. (2010) [4] further subdivided legitimacy into four categories: cognitive, pragmatic, normative and regulative legitimacy, provided a more sophisticated framework for the perspective of organizing vision in study of IT innovation diffusion. Wang and Swanson (2007) [32] took professional services automation (PSA) as research object, they confirmed that the institutional entrepreneurs struggled to legitimate PSA by developing a coherent organizing vision that incorporated compelling success stories, raising the possibility of PSA implementation in the organization. Standing et al. (2013) [33] believed that the organizing visions do not necessarily promote the adoption of IT innovation. Companies rely on organizing visions to judge whether IT innovations have tactical or strategic contribution, in this sense, the key point that decide whether IT innovations have value is not the innovation itself, but the value perception of organizing vision. Thus, when the organizing visions fail to properly perceive the value of IT innovation, it may limit the adoption of IT innovative within the organization [33].

\subsection{Computerization Movement}

Kling and Iacono (1994) [34] defined the computerization movement as "a kind of movement whose advocates focus on computer-based systems as instruments to bring about a new social order... based upon collaborations of participants with diverse interests". In other words, the advocates of computerization movement are trying to establish a new social order through the new IT. As a result, IT innovation has been brought into a broader and more complex macro social environment by computerization movement. The core idea of the computerization movement theory is that the diffusion of IT innovation is not only the product of the scientific research laboratory and the enterprise, but also the product of the social movement.

The main character of the computerization movement is the collective actions, including technological action frames and public discourses. Technological action frame is a comprehensive understanding of how technology works and being used, and it is established in the dynamic process of the interaction between the participants. Public discourse is the expression way of technological action frame and participants ideology, it supports the relationship between computerization and the new social order, and be used to legalize or against the computerization input [31]. Collective actions can promote the movement of computerization by shaping public discourse, and the core of "shaping" is "framing", refers to a process by which social meanings are constructed, disseminated, and stabilized in discourse, namely, the process of the establishment of technological action frames [35]. With the passage of time, in the role of collective actions, the organization may insert beliefs and ideas of computerization movement into practice and adopt IT innovation.

\section{Conclusion and the Prospect of Future Research}

In terms of the impact factors of IT innovation, the research from dynamic perspective is still in its initial stage, and has not formed a complete and clear research system. Combining with the existing research, this paper puts forward the following suggestions: first, the theoretical research from dynamic perspective should be deepened. The current social environment is becoming more and more complex, organizations are inevitable to form a multi-dimensional network of social relations with the external stakeholders, and their behaviors are more disturbed by the outside world, so scholars should focus on exploring the social cognitive dynamics in the context of social network. Second, I carry out multi-perspective integration research. Existing research on the influencing factors of IT innovation diffusion mostly based on single perspective, it is difficult to comprehensively and deeply explore IT innovation diffusion within and between organizations. It is necessary to integrate static and dynamic research perspective in further study. Third, scholars can select the emerging IT innovations as the research object. In recent years, IT innovation tide emerging, such as big data, cloud computing, social media, etc, all of these will bring more research opportunities to scholars. 


\section{References}

[1] Fichman, R.G. (2004) Going beyond the Dominant Paradigm for Information Technology Innovation Research: Emerging Concepts and Methods. Journal of the Association for Information Systems, 5, 314-355.

[2] Melville, N. and Ramirez, R. (2008) Information Technology Innovation Diffusion: An Information Requirements Paradigm. Information Systems Journal, 18, 247-273. http://dx.doi.org/10.1111/j.1365-2575.2007.00260.x

[3] Wang, P. (2009) Popular Concepts beyond Organizations: Exploring New Dimensions of Information Technology Innovations. Journal of the Association for Information Systems, 10, 1-30.

[4] Kaganer, E., Pawlowski, S.D. and Patton, S.W. (2010) Building Legitimacy for IT Innovations: The Case of Computerized Physician Order Entry Systems. Journal of the Association for Information Systems, 11, 1-33.

[5] Daft, R.L. (1978) A Dual-Core Model of Organizational Innovation. Academy of Management Journal, 21, $193-210$. http://dx.doi.org/10.2307/255754

[6] Lind, M.R. and Zmud, R.W. (1991) The Influence of a Convergence in Understanding between Technology Providers and Users on Information Technology Innovativeness. Organization Science, 2, 195-217. http://dx.doi.org/10.1287/orsc.2.2.195

[7] Swanson, E.B. (1994) Information Systems Innovation among Organizations. Management Science, 40, $1069-1092$. http://dx.doi.org/10.1287/mnsc.40.9.1069

[8] Lyytinen, K. and Rose, G.M. (2003) Disruptive Information System Innovation: The Case of Internet Computing. Information Systems Journal, 13, 301-330. http://dx.doi.org/10.1046/j.1365-2575.2003.00155.x

[9] Fichman, R.G., Santos, B.L. and Zheng, Z. (2014) Digital Innovation as a Fundamental and Powerful Concept in the Information Systems Curriculum. MIS Quarterly, 38, 329-353.

[10] Rogers, E.M. (1983) Diffusion of Innovation, Free Press, New York.

[11] Cooper, R.B. and Zmud, R.W. (1990) Information Technology Implementation Research: A Technological Diffusion Approach. Management Science, 36, 123-139. http://dx.doi.org/10.1287/mnsc.36.2.123

[12] Swanson, E.B. and Ramiller, N.C. (2004) Innovating Mindfully with Information Technology. MIS Quarterly, 28, 553583.

[13] Fichman, R.G. and Melville, N. (2014) How Posture-Profile Misalignment in IT Innovation Diminishes Returns: Conceptual Development and Empirical Demonstration. Journal of Management Information Systems, 31, 203-239. http://dx.doi.org/10.2753/MIS0742-1222310109

[14] Wang, P. (2010) Chasing the Hottest IT: Effects of Information Technology Fashion on Organizations. MIS Quarterly, 34, 63-85.

[15] Wang, P. and Ramiller, N.C. (2009) Community Learning in Information Technology Innovation. MIS Quarterly, 33, 709-734.

[16] Attewell, P. (1992) Technology Diffusion and Organizational Learning: The Case of Business Computing. Organization Science, 3, 1-19. http://dx.doi.org/10.1287/orsc.3.1.1

[17] Fichman, R.G. and Kemerer, C.F. (1999) The Illusory Diffusion of Innovation: An Examination of Assimilation Gaps. Information Systems Research, 10, 255-275. http://dx.doi.org/10.1287/isre.10.3.255

[18] Fichman, R.G. and Kemerer, C.F. (1997) The Assimilation of Software Process Innovations: An Organizational Learning Perspective. Management Science, 43, 1345-1363. http://dx.doi.org/10.1287/mnsc.43.10.1345

[19] Sherif, K., Zmud, R.W. and Browne, G.J. (2006) Managing Peer-to-Peer Conflicts in Disruptive Information Technology Innovations: The Case of Software Reuse. MIS Quarterly, 30, 339-356.

[20] Carlo, J.L., Lyytinen, K. and Rose, G.M. (2012) A Knowledge-Based Model of Radical Innovation in Small Software Firms. MIS Quarterly, 36, 865-895.

[21] Saraf, N., Liang, H., Xue, Y. and Hu, Q. (2013) How Does Organizational Absorptive Capacity Matter in the Assimilation of Enterprise Information Systems? Information Systems Journal, 23, 245-267. http://dx.doi.org/10.1111/j.1365-2575.2011.00397.x

[22] Cooper, V. and Molla, A. (2014) Absorptive Capacity and Contextual Factors That Influence Green IT Assimilation. Australasian Journal of Information Systems, 18, 271-288. http://dx.doi.org/10.3127/ajis.v18i3.1099

[23] Roberts, N., Galluch, P.S., Dinger, M. and Grover, V. (2012) Absorptive Capacity and Information Systems Research: Review, Synthesis, and Directions for Future Research. MIS Quarterly, 36, 625-648.

[24] Angst, C.M., Agarwal, R., Sambamurthy, V. and Kelley, K. (2010) Social Contagion and Information Technology Diffusion: The Adoption of Electronic Medical Records in US Hospitals. Management Science, 56, 1219-1241. http://dx.doi.org/10.1287/mnsc.1100.1183 
[25] Teo, H.H., Wei, K.K. and Benbasat, I. (2003) Predicting Intention to Adopt Inter-Organizational Linkages: An Institutional Perspective. MIS Quarterly, 27, 19-49.

[26] Liang, H., Saraf, N., Hu, Q. and Xue, Y. (2007) Assimilation of Enterprise Systems: The Effect of Institutional Pressures and the Mediating Role of Top Management. MIS Quarterly, 31, 59-87.

[27] Baskerville, R. and Myers, M. (2009) Fashion Waves in Information Systems Research and Practice. MIS Quarterly, 33, 647-662.

[28] Swanson, E.B. and Ramiller, N.C. (1997) The Organizing Vision in Information Systems Innovation. Organization Science, 8, 458-474. http://dx.doi.org/10.1287/orsc.8.5.458

[29] Abrahamson, E. (1996) Management Fashion. Academy of Management Review, 21, 254-285.

[30] Hashim, N.H., Murphy, J.M., Doina, O. and O’Connor, P. (2014) Bandwagon and Leapfrog Effects in Internet Implementation. International Journal of Hospitality Management, 37, 91-98. http://dx.doi.org/10.1016/j.ijhm.2013.10.012

[31] Barrett, M., Heracleous, L. and Walsham, G. (2013) A Rhetorical Approach to IT Diffusion: Reconceptualizing the Ideology-Framing Relationship in Computerization Movements. MIS Quarterly, 37, 201-220.

[32] Wang, P. and Swanson, E.B. (2007) Launching Professional Services Automation: Institutional Entrepreneurship for Information Technology Innovations. Information and Organization, 17, 59-88. http://dx.doi.org/10.1016/j.infoandorg.2007.02.001

[33] Standing, S., Standing, C. and Love, P. (2013) How Organizing Visions Influence the Adoption and Use of Reverse Auctions. Electronic Commerce Research, 13, 493-511. http://dx.doi.org/10.1007/s10660-013-9133-0

[34] Kling, R. and Iacono, S. (1994) How Do Office Workers Learn about Computing? Information Technology \& People, 6, 249-269.

[35] Hara, N. and Rosenbaum, H. (2008) Revising the Conceptualization of Computerization Movements. The Information Society, 24, 229-245. http://dx.doi.org/10.1080/01972240802191605 